Article

\title{
Evidence for Strong Kinship Influence on the Extent of Linkage Disequilibrium in Cultivated Common Beans
}

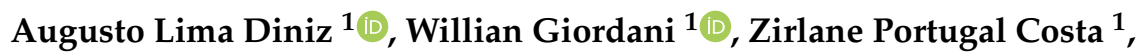 \\ Gabriel R. A. Margarido ${ }^{1}{ }^{\mathbb{D}}$, Juliana Morini K. C. Perseguini ${ }^{2,3}{ }^{\circledR}$, Luciana L. Benchimol-Reis ${ }^{3} \mathbb{D}$, \\ Alisson F. Chiorato ${ }^{4}$, Antônio Augusto F. Garcia ${ }^{1}$ (D) and Maria Lucia Carneiro Vieira ${ }^{1, *}$ (I) \\ 1 Departamento de Genética, Escola Superior de Agricultura “Luiz de Queiroz”, Universidade de São Paulo, \\ Piracicaba, São Paulo 13418-900, Brazil; augustold@usp.br (A.L.D.); giordani.willian@usp.br (W.G.); \\ zirlane26@gmail.com (Z.P.C.); gramarga@usp.br (G.R.A.M.); augusto.garcia@usp.br (A.A.F.G.) \\ 2 Universidade Tecnológica Federal do Paraná, Dois Vizinhos, Paraná 85660-000, Brazil; \\ julianamorini@hotmail.com \\ 3 Centro de Recursos Genéticos, Instituto Agronômico de Campinas, Campinas, São Paulo 13075-630, Brazil; \\ llasry@iac.sp.gov.br \\ 4 Centro de Grãos e Fibras, Instituto Agronômico de Campinas, Campinas, São Paulo 13075-630, Brazil; \\ afchiorato@iac.sp.gov.br \\ * Correspondence: mlcvieir@usp.br; Tel.: +55-19-3429-4395
}

Received: 24 November 2018; Accepted: 18 December 2018; Published: 21 December 2018

\begin{abstract}
Phaseolus vulgaris is an important grain legume for human consumption. Recently, association mapping studies have been performed for the species aiming to identify loci underlying quantitative variation of traits. It is now imperative to know whether the linkage disequilibrium (LD) reflects the true association between a marker and causative loci. The aim of this study was to estimate and analyze LD on a diversity panel of common beans using ordinary $r^{2}$ and $r^{2}$ extensions which correct bias due to population structure $\left(r_{S}^{2}\right)$, kinship $\left(r_{V}^{2}\right)$, and both $\left(r_{V S}^{2}\right)$. A total of 10,362 single nucleotide polymorphisms (SNPs) were identified by genotyping by sequencing (GBS), and polymorphisms were found to be widely distributed along the 11 chromosomes. In terms of $r^{2}$, high values of LD (over 0.8) were identified between SNPs located at opposite chromosomal ends. Estimates for $r_{V}^{2}$ were lower than those for $r_{S}^{2}$. Results for $r_{V}^{2}$ and $r_{V S}^{2}$ were similar, suggesting that kinship may also include information on population structure. Over genetic distance, LD decayed to 0.1 at a distance of $1 \mathrm{Mb}$ for $r_{V S}^{2}$. Inter-chromosomal LD was also evidenced. This study showed that LD estimates decay dramatically according to the population structure, and especially the degree of kinship. Importantly, the LD estimates reported herein may influence our ability to perform association mapping studies on P. vulgaris.
\end{abstract}

Keywords: Phaseolus vulgaris; molecular polymorphism; genotyping by sequencing; population structure; GWAS

\section{Introduction}

The major plant groups traditionally consumed for nutrition include cereals, legumes, tubers, oleaginous plants, and fruits. With some 20,000 species, the legumes (Fabaceae) are the third largest botanical family of angiosperms [1], and include the genus Phaseolus that is of great agricultural interest. This genus is native to the American continent, and contains 55 species, five of which are extensively farmed: Phaseolus vulgaris L., Phaseolus lunatus L., Phaseolus coccineus L., Phaseolus acutifolius A., and Phaseolus polyanthus Greenman [2]. The common bean (P. vulgaris, $2 n=22$ ) is the most 
important species, and two clearly distinct gene pools have been identified-one Andean and the other Mesoamerican-whose molecular diversity and phenotypical characteristics, as well as their population structure and evolutionary dynamics, have been fully described in the literature [2-6]. Furthermore, the common bean is an important source of human nutrition. It is rich in protein and carbohydrates, and provides various nutrients essential for human health.

A number of research groups around the world have been studying the common bean in order to improve the crop, with the aim of developing more productive cultivars that are tolerant to biotic and abiotic stresses, and to boost the nutritional and technological value of the grains $[7,8]$. In this scenario, molecular markers have been extensively used to define the genetic architecture of agronomic traits by mapping quantitative trait loci (QTL) and estimating how many and which QTL are responsible for the phenotypic variation in the populations studied, finding their genome positions, estimating their effects and identifying interrelationships. To map QTL, it is assumed that there is linkage disequilibrium (LD), also known as gametic phase disequilibrium [9], a preferential association between loci (or haplotypes) which are transmitted as sets down through the generations [10]. In the common bean, QTL mapping has entailed linkage analysis based on endogamic populations [11-18].

Association mapping, also known as LD mapping or genome-wide association studies (GWAS), is one mapping alternative for linkage analysis, allowing better use of the genetic variation within the population and providing greater resolution in the identification of QTLs [19]. Association mapping is based on detecting genotype-phenotype associations in populations usually made up of accessions collected from the natural environment or germplasm banks. For the common bean, GWAS studies have been carried out to detect loci involved in the response to stresses caused by pathogens such as Xanthomonas axonopodis pv. phaseoli [20], Colletotrichum lindemuthianum, Pseudomonas syringae [21] and Pseudocercospora griseola [22], water stress [23], as well as loci involved in controlling agronomic traits [24-27] and bean cooking time [28].

To carry out GWAS experiments, it is necessary to know the genomic extent of LD and thereby define the population size and marker density, as well as the size of the LD physical window that flanks the causal polymorphism $[29,30]$. In this respect, a number of proposals have been put forward for assessing the statistical association among the alleles at different loci [31], the majority expressed as covariance functions or genotype correlations. The most widely used parameter is the $r^{2}$ value, which can be defined as the square of the loci correlation [32].

In regard to GWAS, only the LD produced by physical linkage is of interest. For this reason, the population structure and kinship among individuals within the population are commonly taken into account during mapping in order to avoid the detection of false associations [33]. However, the usual measurements of LD, such as $r^{2}$, do not incorporate this correction factor, resulting in biased estimates and leading to inappropriate marker density choices which impair association tests [34]. In an attempt to work around this problem, Mangin et al. [34] proposed extensions to the usual measurement $\left(r^{2}\right)$ in order to control the bias introduced by population structure $\left(r_{\mathrm{S}}^{2}\right)$ or kinship $\left(r_{\mathrm{V}}^{2}\right)$ between individuals in the population under examination, as well as combining both $\left(r_{\mathrm{VS}}^{2}\right)$. Plant studies that incorporate this correction have been carried out recently, for instance on eggplant (Solanum melongena L.) [35], barley (Hordeum vulgare L.) [36], cultivated beets (Beta vulgaris L.) [37], oat (Avena sativa L.) [38], pear (Pyrus spp.) [39], and the common grapevine (Vitis vinifera L.) [40].

Studies focused on estimating the LD extension based on $r^{2}$ across the P. vulgaris genome [4,22,41-45] report LD estimations as high as $100 \mathrm{cM}$ [41]. However, when accession classification into the gene pool was considered, reduced LD levels were detected, suggesting that population structure may explain the high estimate of LD between loci [46]. Valdisser et al. [47] and Resende et al. [48] also estimated the extent of LD, correcting for bias due to both population structure and kinship, and detected strong LD decay. Nevertheless, for the common bean, the relative importance of each of these factors on LD measurement is still unknown, since they were not evaluated independently in these studies. 
In this scenario, the aims of the present study are to investigate the relative influence of population structure, kinship, and the combination of both to the LD estimates in a common bean diversity panel, as well as to provide a detailed examination of the intra- and inter-chromosomal LD patterns based on thousands of single nucleotide polymorphisms (SNPs).

\section{Materials and Methods}

\subsection{Plant Material}

This study was based on a panel of 180 common bean genotypes, as shown in Figure 1, representative of the genetic diversity of a common bean germplasm repository of 1800 accessions, deposited at the Agronomic Institute (IAC) in Campinas, Brazil. The IAC, founded in 1887, is an important research institute of São Paulo state's Department of Agriculture and Supply. The panel included commercial cultivars from different breeding institutions, landraces, and parents of the following populations: 'Bat 93' × 'Jalo EEP 558' [49]; 'Carioca' × 'Flor de Mayo' [50]; and 'CAL 143' $\times$ 'IAC UNA', and also $14 \mathrm{~F}_{10}$ recombinant inbred lines (RILs) derived from the 'CAL 143 ' $\times$ 'IAC UNA' cross [16]. In addition to 87 inbred lines from the IAC breeding program, the diversity panel studied herein includes 62 common bean lines from the International Center for Tropical Agriculture (CIAT), 12 from the Brazilian Agricultural Research Corporation (Embrapa), as well as nine Brazilian landraces and ten cultivars [51]. Phenotypically, this panel contains variability in (i) grain morphology, (ii) resistance to biotic factors such as pests and diseases, (iii) tolerance to abiotic factors such as drought, and (iv) the micronutrient composition of grains [51]. The 180 accessions were classified according to: (i) institution of origin (62 from CIAT, 87 from IAC, 12 from Embrapa, 1 from each of EPAGRI (Santa Catarina State Rural Extension and Agricultural Research Enterprise) and FEPAGRO (State Foundation for Agricultural Research), 2 from FT Sementes, 4 from IAPAR (Agronomic Institute of Parana), 1 from UEM (State University of Maringa), 1 from UFLA (Federal University of Lavras), and 9 landraces); (ii) type of phaseolin (27 T-type and 153 S-type, of Andean and Mesoamerican origin, respectively), following the methodology proposed by Kami et al. [52]; (iii) grain size (42 small, 113 medium, and 25 large), and (iv) commercial group (1 'Amendoim', 45 'Black', 80 'Carioca', 8 'Creme', 4 'Jalo', 10 'Mottled', 8 'Mulatinho', 5 'Pink', 2 'Pinto Beans', 6 'Red', 6 'White', 4 'Yellow', and 1 'Zebra'), as shown in Table S1.

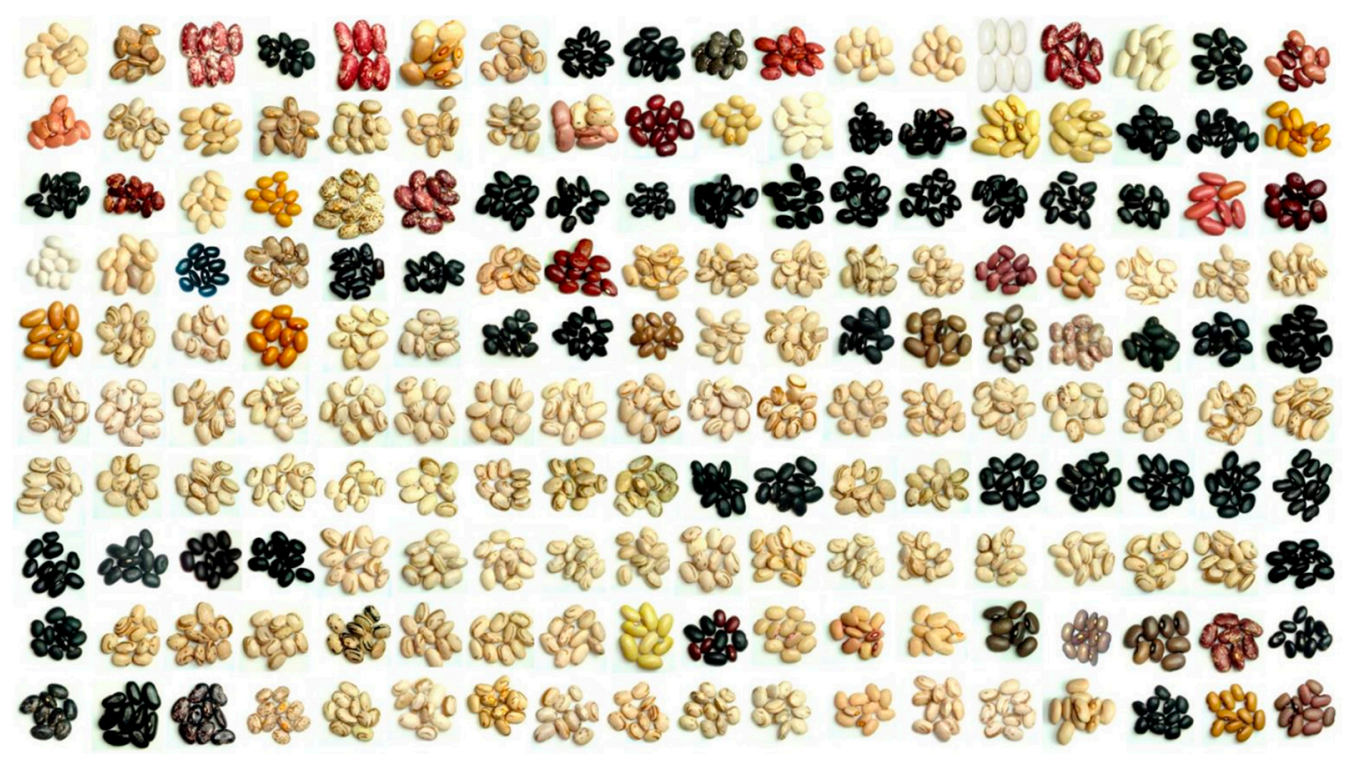

Figure 1. Phenotypic seed diversity encompassed by 180 accessions of a common bean panel. 


\subsection{DNA Extraction, Genotyping by Sequencing Library Preparation, Sequencing, and SNP Calling}

Total genomic DNA from the IAC panel genotypes $(n=180)$ was extracted from young leaves collected from 10 plants per accession using the DNeasy ${ }^{\circledR}$ Plant Mini Kit (Qiagen, Venlo, Netherlands) according to the manufacturer's instructions. DNA concentration was assessed using spectrophotometry (NanoDrop 2000, Thermo Scientific, Waltham, MA, USA) and agarose gel electrophoresis $(0.8 \% w / v)$. Sample DNA intensities were compared to a DNA quantitation standard after staining with SYBR SAFE ${ }^{\circledR}$ (Invitrogen, Carlsbad, CA, USA). To check DNA integrity, $500 \mathrm{ng}$ from 20 randomly selected genotypes was subjected to restriction digestion using HindIII (New England BioLabs ${ }^{\circledR}$, Ipswich, MA, USA) according to the manufacturer's instructions, followed by electrophoresis on SYBR SAFE ${ }^{\circledR}$ (Invitrogen) stained agarose gel $(0.8 \% w / v)$.

Two genotyping by sequencing (GBS) libraries were constructed in 95-plex. For each library, a single random blank well was included for quality control to ensure that libraries were not switched during construction, sequencing, and analysis. Genomic DNA was co-digested with the restriction enzyme ApeKI ( $5^{\prime}$ CWGC $3^{\prime}$ ) and barcoded adapters were ligated to individual samples. The samples were pooled by plate into libraries and amplified by polymerase chain reaction. Detailed protocols can be found in Elshire et al. [53]. Each library was single-end sequenced to $100 \mathrm{bp}$ in a single lane of HiSeq 2500 (Illumina, San Diego, CA, USA.). These procedures were carried out at the Genomic Diversity Facility, Institute of Biotechnology, Cornell University, USA.

Sequences from two ApeKI-GBS libraries from the IAC panel can be downloaded from GenBank BioSample SAMN05513252 and SAMN05513251, both included in BioProject PRJNA336556.

The TASSEL-GBS bioinformatics pipeline [54], designed for efficiently processing raw GBS sequence data into SNP genotypes, was used in the present study. Sequences from an inbred landrace line of $P$. vulgaris (G19833) were set as the reference genome [55]. Initial filtering was based on the following settings: (i) minor allele frequency (MAF) $\geq 0.01$ and (ii) minimum coefficient of inbreeding 0.9 .

\subsection{Filtering and Imputing Genotyping by Sequencing SNP Calls}

Only SNPs in the assembled chromosomal pseudomolecules of P. vulgaris were selected. Exploratory analyses were conducted in order to verify the proportion of missing and heterozygous data for each SNP data set. Because P. vulgaris is predominantly autogamous, the occurrence of heterozygotes is negligible [12], as shown in Figure S1. We therefore assumed that these cases were possible sequencing errors and treated them as missing data. A 10\% threshold for missing data was set prior to imputing. The method proposed by Roberts et al. [56] was used for imputing missing/unknown SNP data. This method is particularly suitable for inferring missing genotype information in large sets of SNPs from inbred lines, based on the information at adjacent loci, i.e., the existence of LD between loci (haplotypes). Accuracy is increased based on the prediction of known genotypes and the method is widely used for autogamous species. Initially, to determine the optimal number of loci to be set as the imputing window size, we evaluated five to 150 loci and selected the one with the highest accuracy. The window size was set, and the NPUTE package [56] was used to perform data imputation chromosome-by-chromosome. Then a 5\% MAF threshold was set and the remaining SNPs were used for determining population structure, kinship, and LD analysis.

\subsection{Population Structure, Kinship, and Linkage Disequilibrium Investigation}

Principal component analysis (PCA) was applied to investigate population structure, via the 'prcomp' function implemented in the R statistical package [57], and a Tracy-Widom statistic test was used to define the number of significant principal components (PCs) [58,59]. The criteria for determining the number of PCs used as a population structure (S) matrix for LD measurements were based on (i) the proportion of variance explained by each PC and (ii) graphic visual inspection of the 
dispersion of PC scores. Therefore, we used the first four PC values as the ' $\mathrm{S}$ ' matrix. In addition, nucleotide diversity $\pi$ [60] was estimated using MEGA5 [61].

A relatedness matrix was estimated from genotype data using the simple matching coefficient, extended to include loci that are identical by state but not by descent [62], according to Equation (1):

$$
\frac{S-S_{\min }}{1-S_{\min }}
$$

where $S$ is the matrix of simple matching coefficients corrected by the minimum of observed simple matching coefficients, $S_{\min }$. The 'kin' function in the synbreed package of the R platform [63] was used with argument ret $=$ "sm - smin".

Linkage disequilibrium, the non-random association of alleles at two different loci, was estimated by squared allele-frequency correlations using R package "LDcorSV" [34]. Four LD estimates were calculated: conventional $r^{2}$ based only on genotype data, $r^{2}$ correcting for population structure bias $\left(r_{S}^{2}\right), r^{2}$ taking account of kinship $\left(r_{V}^{2}\right)$, and $r^{2}$ with both population structure and kinship included $\left(r_{V S}^{2}\right)$. The p-values for each test were obtained by applying Fisher's exact test run using the 'LD' function implemented in R package "genetics" [64]. In addition, the false discovery rate (FDR) was controlled by selecting tests with significance of $5 \%$ [65].

LD decay over genetic distance was investigated by plotting pairwise LD values against the distance between loci on the same chromosome. It was modelled by matching a modified recombination-drift model [66], including a low level of mutation and adjustment for sample size, using the Hill and Weir [67] expectation of $r^{2}$ between adjacent sites, according to Equation (2):

$$
E\left(r^{2}\right)=\left[\frac{10+C}{(2+C)(11+C)}\right]\left[1+\frac{(3+C)\left(12+12 C+C^{2}\right)}{n(2+C)(11+C)}\right]
$$

where $n$ is the sample size, and $C$, the parameter to be estimated, represents the product of the population recombination parameter $\rho=4 N_{e} r$ and the distance in base pairs. Finally, heatmaps were produced based on pairwise LD measurements for all marker pairs within each chromosome in order to visualize intra-chromosomal LD patterns. Additionally, inter-chromosomal LD was investigated based on $r_{V S}^{2} \geq 0.7$, comparing SNPs located on different chromosomes.

\section{Results}

\subsection{Single Nucleotide Polymorphism Calling and Imputation}

After sequencing the two GBS libraries from the IAC panel, a total of 428,404,611 reads were obtained, of which 399,296,160 (93.2\%) were of high quality, and 3,018,395 tags were identified. Regarding alignment, 1,678,051 (55.6\%) aligned to single positions on the reference genome of $P$. vulgaris and 163,651 (5.4\%) aligned to multiple regions. Finally, 83,364 SNPs were identified on chromosomal pseudomolecules and 684 on scaffold sequences from the reference genome.

As the frequency of heterozygous genotypes was practically null, as shown in Figure S1, we assumed these cases to be possible sequencing errors and therefore treated them as missing data. The proportion of missing data was less than $50 \%$ for over $70 \%$ of the loci identified.

In the process of replacing missing data, the number of loci per window size varied from 10 (Pv09) to 22 (Pv07), as shown in Table S2. In terms of MAF distribution, imputation did not make any significant difference to the final data set, since a very conservative threshold for missing data was applied, as shown in Figure S2.

Finally, after filtering, a total of 10,362 SNPs were identified, as shown in Table 1. Polymorphisms were widely distributed along the 11 chromosomes of $P$. vulgaris, although not uniformly (a higher SNP density was found near the chromosome ends). The chromosome position, alleles, and MAFs of filtered SNPs are given in Table S3. 
Table 1. Number of single nucleotide polymorphisms (SNPs) per chromosome of Phaseolus vulgaris generated by ApeKI-GBS (genotyping by sequencing) technology in the IAC (Agronomic Institute) diversity panel.

\begin{tabular}{ccccc}
\hline & & & \multicolumn{2}{c}{ Number of SNPs } \\
\hline Chromosome & Physical Length (Mb) $\mathbf{1}^{\mathbf{1}}$ & Number of Genes & MD $\leq \mathbf{0 . 1 0}$ & MAF $\geq \mathbf{0 . 0 5}$ \\
\hline Pv01 & 52.18 & 2116 & 2100 & 993 \\
Pv02 & 49.03 & 2695 & 2678 & 1261 \\
Pv03 & 52.21 & 2294 & 2407 & 1063 \\
Pv04 & 45.79 & 1035 & 1378 & 748 \\
Pv05 & 40.23 & 1349 & 1335 & 695 \\
Pv06 & 31.97 & 1649 & 1635 & 841 \\
Pv07 & 51.69 & 2146 & 2133 & 1082 \\
Pv08 & 59.63 & 2067 & 2453 & 1188 \\
Pv09 & 37.39 & 2134 & 1935 & 869 \\
Pv10 & 43.21 & 1020 & 1379 & 680 \\
Pv11 & 50.20 & 1274 & 1848 & 942 \\
Total & - & 19,779 & 21,281 & 10,362 \\
\hline
\end{tabular}

MD: missing data; MAF: minor allele frequency. ${ }^{1}$ According to the Phaseolus vulgaris reference genome [55].

\subsection{Population Structure and Kinship}

According to PCA, the first PC accounted for the majority (37.4\%) of genetic variation, as shown in Figure 2A, and was generally consistent with prior gene pool classification-Andean vs. Mesoamerican, as shown in Figure 2B. The second PC accounted for $4.3 \%$ of the variation and revealed substructuring among the Mesoamerican accessions, in which nine accessions from CIAT were clearly differentiated from the others. Combining the first two PCs, four groups were formed, the largest of which includes 144 phaseolin type " $\mathrm{S}$ " accessions, with no relationship between the grouping and the institution of origin. This group also includes all IAC accessions with typically 'carioca' grains (51), and most of the accessions with typically 'black' grains (18), both of considerable commercial interest in Brazil.

A further two separate groups were, for the most part, accessions originating from CIAT. One of them includes only " $\mathrm{S}$ " accessions, and the other consists mainly (9 accessions) of " $\mathrm{T}$ " accessions of Andean origin, with the large grains typical of this gene pool. In addition, nucleotide diversity analysis, as shown in Table 2, suggests that the CIAT collection $(\pi=0.309)$ is more diverse than IAC, Embrapa, and accessions from other institutions.

Table 2. Nucleotide diversity in a common bean diversity panel, based on SNPs generated by ApeKI-genotyping by sequencing (GBS) technology. CIAT: International Center for Tropical Agriculture.

\begin{tabular}{cccc}
\hline Institution of Origin & $\mathbf{N}$ & $\mathbf{S}$ & $\boldsymbol{\pi}$ \\
\hline IAC & 87 & 10,354 & 0.256 \\
CIAT & 62 & 10,346 & 0.309 \\
Embrapa & 12 & 9632 & 0.272 \\
Other & 19 & 9984 & 0.251 \\
Total & 180 & 10,362 & 0.277 \\
\hline
\end{tabular}

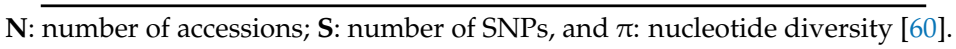

Finally, there was a separate group including the $14 \mathrm{~F}_{10}$ recombinant inbred lines (RILs) produced by bi-parental crossing of the accessions 'CAL 143' (Andean) and 'IAC Una' (Mesoamerican) $[16,17,68,69]$. Estimating the degree of kinship once again revealed that there was a tendency for accessions from the same breeding institution to cluster together, as shown in Figure 2C. 

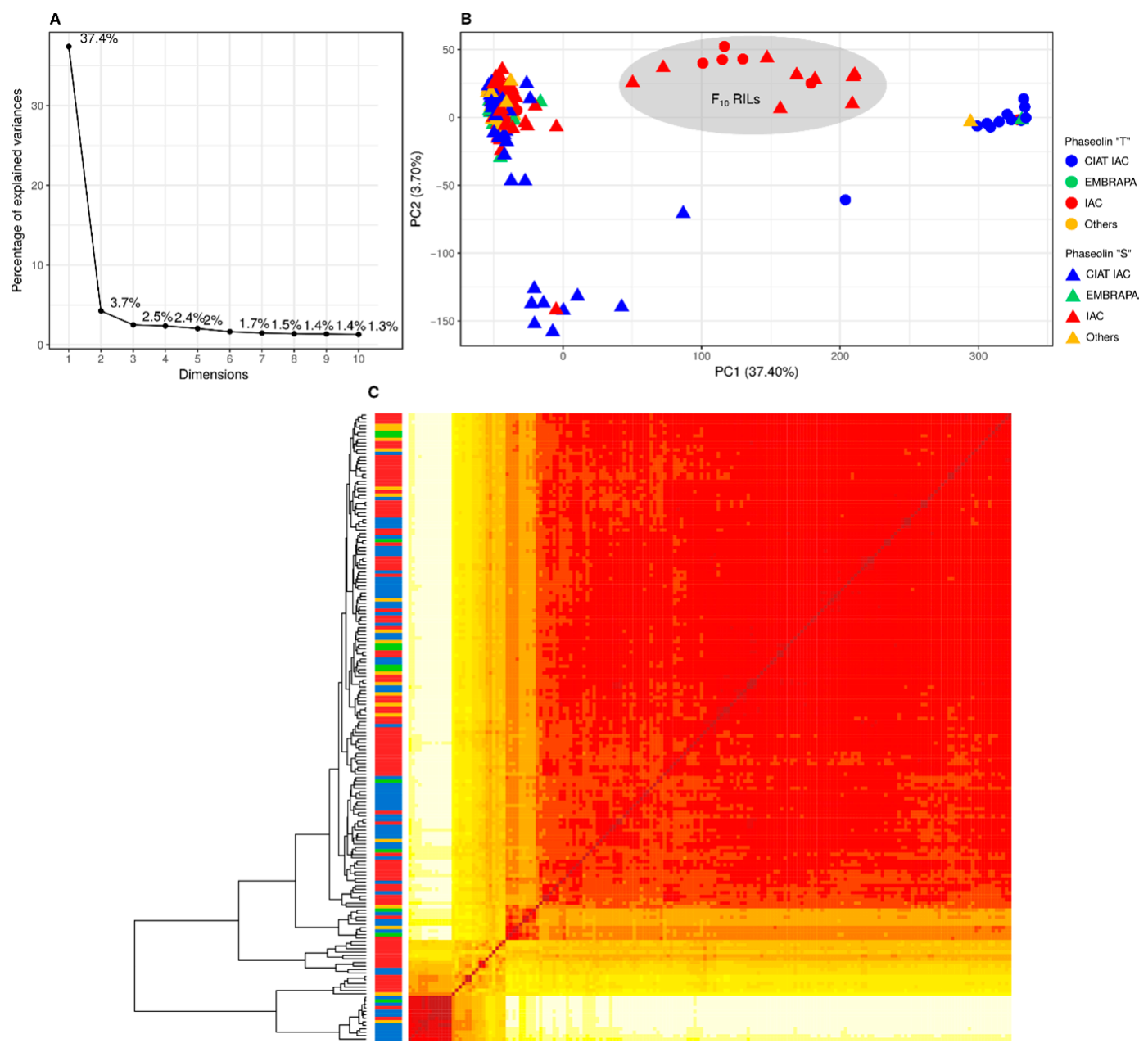

Figure 2. Population structure inferred by principal component analysis (PCA) (A and B) and the dendrogram and the heatmap (C) of a kinship matrix estimated by the simple matching coefficient, extended to account for loci that are identical by state but not identical by descent, based on 10,362 single nucleotide polymorphism (SNP) markers (minor allele frequency $>5 \%$ ), among 180 genotypes from the IAC diversity panel. The colored shapes (B) were classified in two groups in accordance with the type of phaseolin: " $\mathrm{T}$ " (circle) and " $\mathrm{S}$ " (triangle), which have Andean and Mesoamerican origin, respectively. The colors shown in B and the scale between the dendrogram and the heatmap (C) corresponds to the breeding institution.

\subsection{Linkage Disequilibrium}

Analyzing the $r^{2}$ values calculated for SNP pairs in the same chromosome, there is a tendency for average LD values to decrease as the distance between loci increases, as shown in Figure 3. However, values of $r^{2}>0.8$ were detected between pairs of SNPs at a distance of $10 \mathrm{Mb}$ and between SNPs at opposite ends of the chromosome.

In contrast, distinct LD patterns were obtained when the measurements that control the bias introduced by population structure $\left(r_{S}^{2}\right)$, kinship $\left(r_{V}^{2}\right)$, and both combined $\left(r_{V S}^{2}\right)$ were taken into account. In all cases, there was a drastic decrease in the LD estimates, although they remained high between closely linked loci. Compared to $r_{S}^{2}$, the estimates of $r_{V}^{2}$ were lower overall, showing that the bias ascribed to kinship was higher compared to that ascribed to population structure. Furthermore, the results obtained for $r_{V}^{2}$ and $r_{V S}^{2}$ were very similar, suggesting that kinship includes information on population structure. Regardless of the correction applied, the largest blocks of loci with high LD were detected in the centromeric and pericentromeric regions, in which recombination is inhibited. However, there were also blocks in the distal region of the long arm of chromosomes Pv06 and Pv09. 

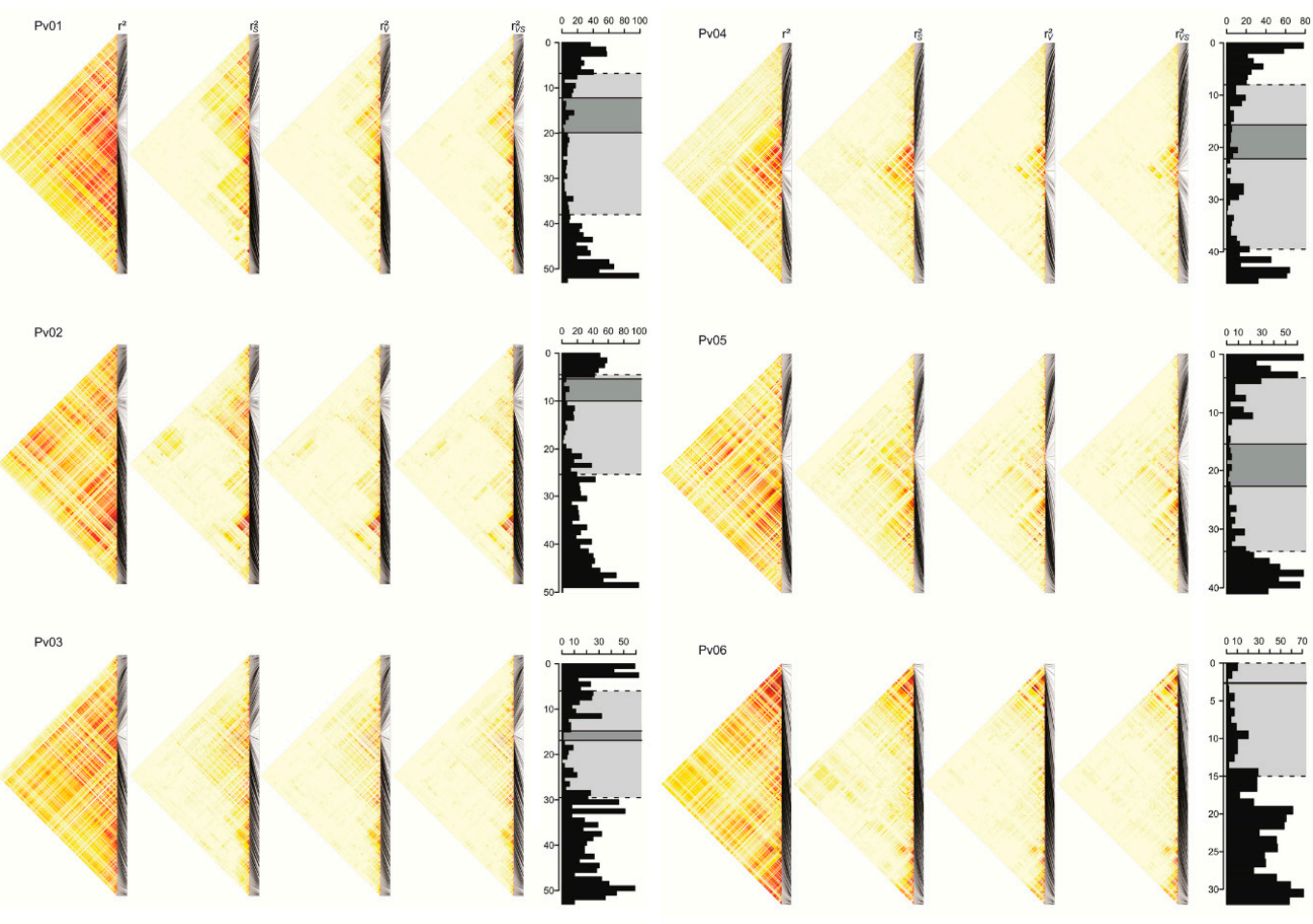

(A)
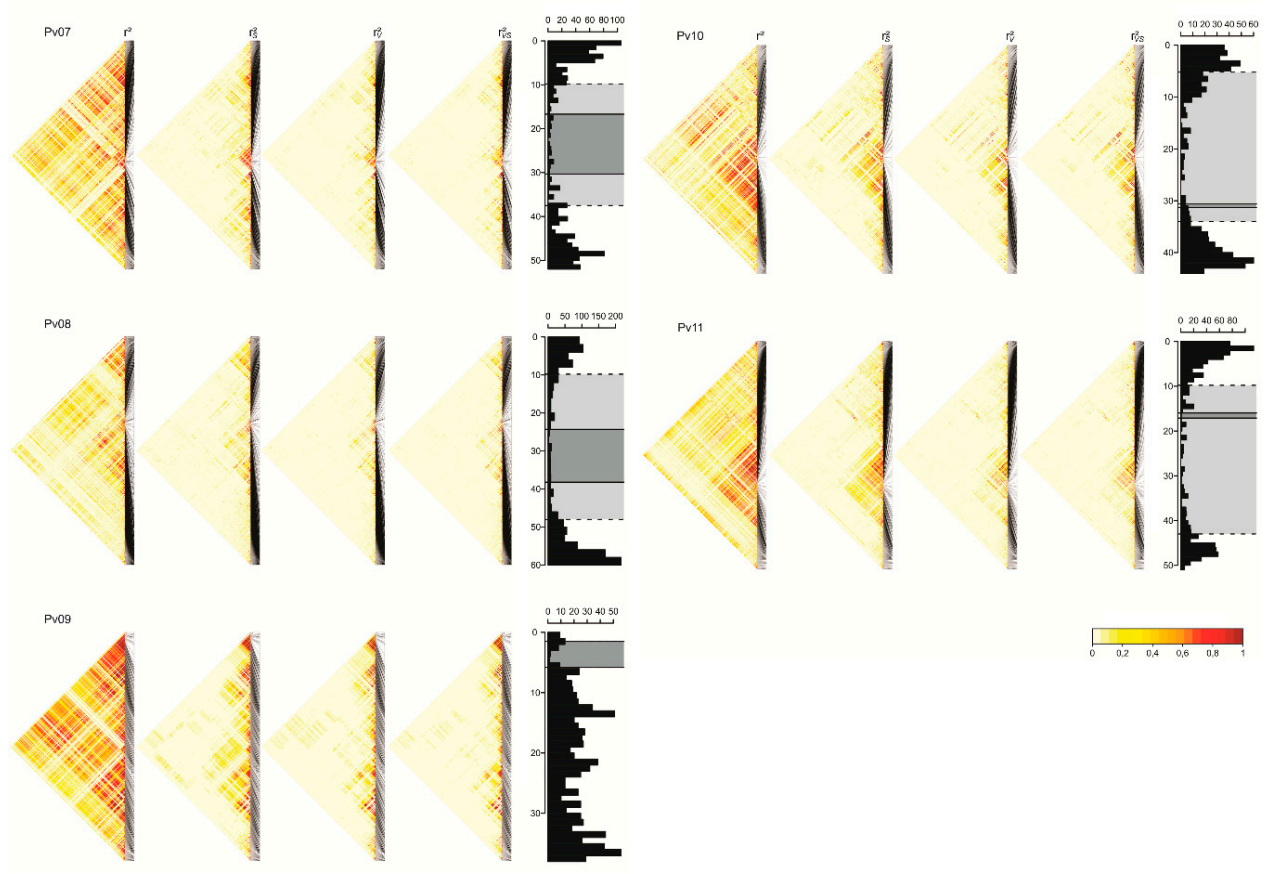

(B)

Figure 3. Linkage disequilibrium (LD) patterns in cultivated Phaseolus vulgaris from the IAC diversity panel. Histograms indicate SNP density along the chromosome: (A) chromosomes Pv01 to Pv06; (B) chromosomes Pv07 to Pv09. Ordinate and abscissa correspond to the loci position (Mb) and number of SNPs, respectively. The areas delimited by continuous and dashed lines correspond to centromeric and pericentromeric regions, respectively. LD heatmaps are shown for $r^{2}$ measurements and extensions correcting bias from population structure $\left(r_{S}^{2}\right)$, kinship $\left(r_{V}^{2}\right)$, and both combined $\left(r_{V S}^{2}\right)$. The degree of $\mathrm{LD}$ is indicated by colors from light yellow (no LD) to red (strong LD). 
When adjusted to fit the model proposed by Hill and Weir [67] regarding estimated LD $\left(r^{2}\right)$ as a function of distance, there was subtle decay observed. However, when the biases ascribed both to population structure and kinship were taken into account, LD decayed to 0.1 at distances of around $1 \mathrm{Mb}$, and again very similar results were obtained for $r_{V}^{2}$ and $r_{V S}^{2}$, as shown in Figure 4.

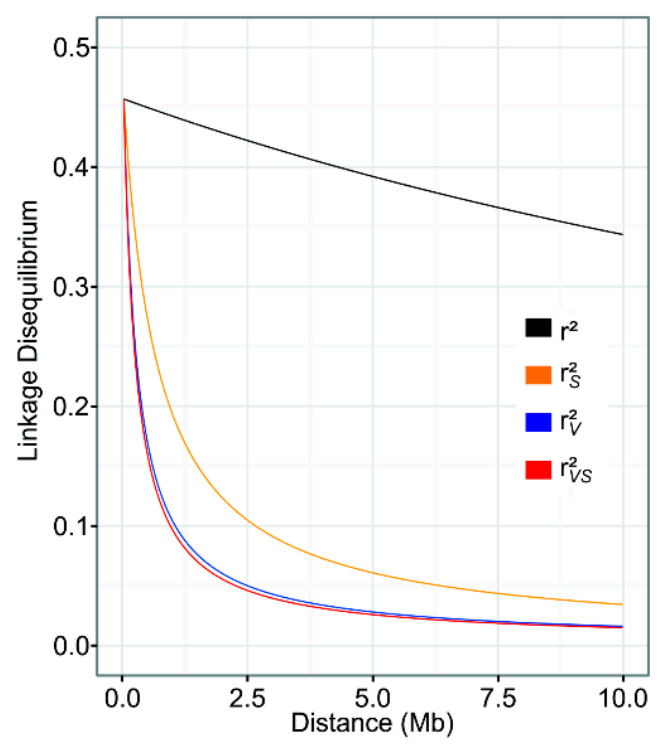

Figure 4. Linkage disequilibrium (LD) decay determined by four LD measurements against distance between SNPs within the chromosome, adjusted by the mutation model.

Even using $r_{V S}^{2}$, high LD values $(\geq 0.7)$ were detected between 671 SNP pairs located in different chromosomes, revealing inter-chromosomal LD patterns, as shown in Figure 5. We found values of $r_{V S}^{2} \geq 0.9$ between two loci from Pv01, with 20 and 16 others distributed respectively on Pv07 and Pv08. Furthermore, preferential associations between a locus on Pv08 with loci on the pericentromeric region of Pv11 were detected.

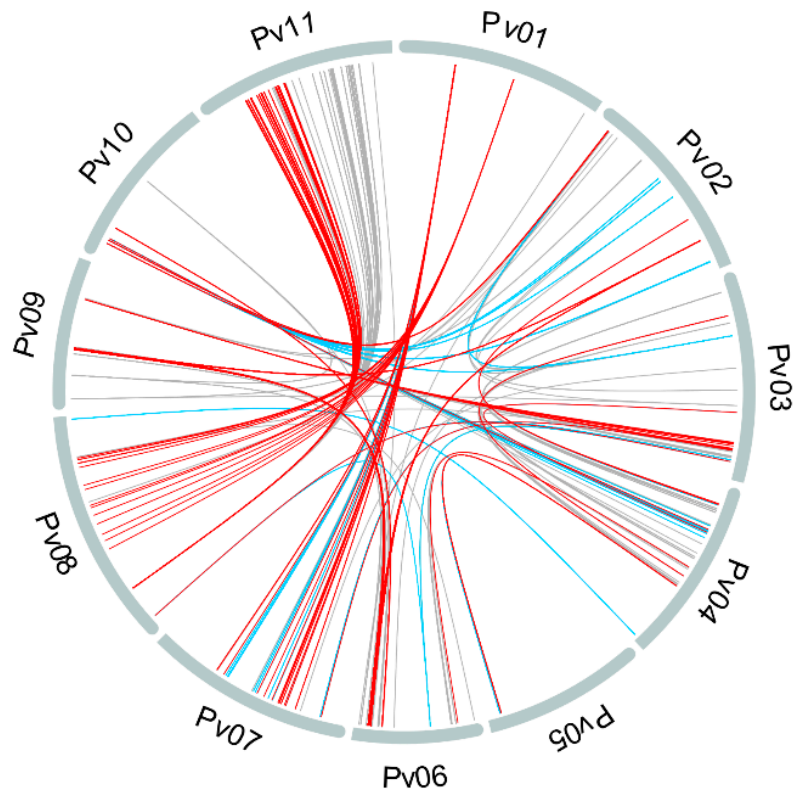

Figure 5. Inter-chromosomal linkage disequilibrium (LD) in Phaseolus vulgaris. Gray, blue, and red lines connecting chromosomes correspond to LD estimates between SNP pairs in which $r_{V S}^{2} \geq 0.7,0.8$, and 0.9 , respectively. 


\section{Discussion}

In this study, we examined intra- and inter-chromosomal LD patterns in 180 genotypes of cultivated beans from a diversity panel based on information on 10,362 high-quality SNPs. Random sequencing coverage of genomic regions from different samples and mutations at restriction sites resulted in missing data, due to the GBS technique [53]. Nevertheless, the percentage of missing data was $<50 \%$ for the majority $(>70 \%$ ) of the SNPs analyzed herein. In addition, since a very conservative threshold for missing data was applied, the imputation step did not result in significant differences in the final data set. We performed the Pearson's correlation estimation between the two data sets (before and after imputation), which are over 98\% correlated. The distribution of SNPs was not uniform along the chromosomes. This is due to the reduction in genome complexity when libraries are built by enzymatic hydrolysis of the DNA using ApeKI, whose activity is inhibited in methylated regions. As expected, centromeric and pericentromeric regions, identified in silico by gene density and repetitive elements [55], exhibited lower SNP density.

\subsection{Population Structure and Kinship}

In terms of PCA, the first two principal components accounted respectively for $37.4 \%$ and $4.3 \%$ of genetic variation, as shown in Figure $2 \mathrm{~A}$. This allowed us to classify the gene pools coherently as Andean vs. Mesoamerican, with the exception of $14 \mathrm{~F}_{10}$ RILs, as shown in Figure 2B, which were inter-pool hybrids produced by crossing the accessions 'CAL 143' (Andean) and 'IAC Una' (Mesoamerican). Furthermore, PCA revealed Mesoamerican accession substructuring, which corroborated earlier reports indicating that the Mesoamerican pool contains more diversity than the Andean pool [4,5,70]. Within the Mesoamerican pool, the 144 phaseolin type "S" accessions consisted of plants with medium-sized or small seeds-a typical Mesoamerican characteristic-lending weight to a classification based on the phaseolin protein. In addition, the remaining nine Mesoamerican CIAT accessions were distinguished from the others, indicating higher diversity of the CIAT collection compared those of the other institutions, as confirmed by the nucleotide diversity analysis, as shown in Table 2.

The IAC diversity panel contained accessions from different breeding institutions. Although not as strong due to significant germplasm exchange between breeding programs, kinship estimation revealed a bias for grouping accessions according to these institutions, as shown in Figure 2C. Since a select group of parents is preferentially used to produce commercial varieties at breeding institutions, the genetic base can sometimes be narrow, and a significant degree of kinship is to be expected among genotypes from the same breeding institution.

\subsection{Linkage Disequilibrium}

Estimates of LD varied from one chromosomal region to another and were higher in pericentromeric regions. Similarly, in the soybean, it has been reported that LD is negatively correlated $(r=-0.47)$ with recombination rates in these regions [71]. In our study, estimates based on the ordinary measurement $\left(r^{2}\right)$ indicated that LD remains high even between loci at opposite ends of the chromosome. Recently, very similar results were obtained for the common bean, and Valdisser et al. [47], studying a core collection genotyped by the DArTseq high-density SNP approach, reported that $r^{2}$ does not reflect the decay of LD over physical position, and Blair et al. [43] also reported that LD measured by $r^{2}$ decays slowly as a function of genetic and physical distances.

In many cases, $r^{2}$ clearly overestimates LD along a chromosome, which can be explained by various factors, such as artificial selection, population structure, and the occurrence of inbreeding or kinship between the genotypes within a population [34]. When studying LD in P. vulgaris, some authors group the genotypes according to the population structure prior to $r^{2}$ estimation and compute this measurement independently for each gene pool. For instance, Rossi et al. [46] and Valdisser et al. [47] evaluated the effect of population structure on LD and found differences between Andean and 
Mesoamerican gene pools, indicating that population structure is a significant factor influencing the magnitude of LD in common bean. These studies reported slower LD decay for the Andean population compared to the Mesoamerican. Similarly, Blair et al. [43] demonstrated clear gene pool differences, with the majority of LD explained by population structure. In addition, we found that the IAC panel revealed substructuration within gene pools, especially for Mesoamerican genotypes, where LD was stronger and decayed more slowly. These different substructures below gene pool level may also influence LD, and as shown by Kwak and Gepts [4], LD estimates in further subdivisions are not accurate, due to small sample size populations, a limitation that can be overcome by applying the appropriate correction to $r^{2}$.

In order to account for population structure and kinship, we applied three different corrections to $r^{2}$, as proposed by Mangin et al. [34]. Our results show that the $r_{S}^{2}, r_{V}^{2}$, and $r_{V S}^{2}$ measurements may help to tackle the problem of the bias introduced by linkage disequilibrium estimates, especially those resulting from the population structure or relatedness of individuals. The IAC panel consists of cultivated accessions and includes lines derived from advanced breeding stages, thus presenting higher LD than expected for wild populations. This kind of comparative analysis has already been conducted; for instance, Rossi et al. [46] found a mean $r^{2}$ of 0.08 and 0.18 in wild and domesticated beans, respectively.

As expected, when we analyzed the highly structured IAC panel, the $r_{S}^{2}$ estimate improved the correction of $r^{2}$ bias, although this was not sufficient to eliminate all the bias due to relatedness. Our results show further advantages for using $r_{V}^{2}$ to account for the kinship bias, indicating that the bias ascribed to kinship is higher than that ascribed to population structure. Furthermore, the similar results obtained for $r_{V}^{2}$ and $r_{V S}^{2}$ suggest that population structure is already taken into account in kinship estimation, especially since accessions from the same pool are closely related. Similar results have already been reported for other species, such as cultivated beets (Beta vulgaris L.) [37], oat [38], and grapevine (Vitis vinifera L) [40].

Interestingly, even working on a highly structured panel, $r_{V}^{2}$ may have advantages over $r_{S}^{2}$, revealing that in some cases modeling genetic relationships by the kinship matrix may be enough to correct the LD bias. Furthermore, our findings suggest that the degree of kinship among individuals in the population under study is worth of special attention. In panels substantially consisting of improved lines, such as those used herein, the bias induced by kinship is stronger than that of population structure itself.

Even using parameters that, in theory, remove most of the bias from $r^{2}$ values, we found that LD in P. vulgaris decayed to 0.1 at a distance of $1 \mathrm{Mb}$ between loci, indicating fairly widespread LD within the species, in contrast to that observed in cultivars of soybean and rice. In these cases, the authors reported decays at a distance between loci of $133 \mathrm{~kb}$ (Glycine max [71]), $123 \mathrm{~kb}$ (Oryza sativa Indica [72]), and $167 \mathrm{~kb}$ (Oryza sativa Japonica [72]). For the common bean, the decay reported herein is slower, even compared to other studies in which structure and kinship bias was corrected, and reporting a decay to 0.1 at around $400 \mathrm{~Kb}$ [47] and $700 \mathrm{~Kb}$ [48]. Nonetheless, the fit of the LD decay curve should be interpreted with caution, since there are regions in which LD decays rapidly, showing that there are specific patterns in the common bean genome. The existence of large LD blocks in the distal region of the long arm of chromosomes Pv06 and Pv09 corroborates the results obtained by Bhakta et al. [73]. These authors determined the recombination rate along arms of individual bean chromosomes. For instance, both arms of chromosome 6 are dominated by a block of rDNA repeats that interferes with the recombination activity.

Inter-chromosomal LD was recently reported by Campa et al. [44] in the common bean, but with different patterns compared to those we found for the IAC panel. The fact that inter-chromosomal LD has been observed, even taking into account the correction for population structure and kinship bias, implies that the breeding process may contribute to LD magnitude. According to Perseguini et al. [22], population mating systems could heavily influence LD patterns in P. vulgaris, as well as epistatic effects, which have been reported to control seed yield and other agronomic traits in an Andean $\times$ 
Mesoamerican cross [74]. Furthermore, diverse LD patterns may also be associated with domestication events for the Andean and Mesoamerican gene pools, which selected indirectly for different chromosomal regions $[44,55]$.

The GWAS method is based on the detection of genotype-phenotype associations in populations consisting of genotypes originating from natural populations and germplasm bank accessions. These populations often span many generations and it is assumed that multiple recombination events have occurred, reducing the extent of genomic regions affected by LD. The results of this study show that the marker density required for reasonable coverage of the genome depends on the particular features of the common bean genome and the chromosomal context. Additional studies to explore patterns of specific genomic segments with reduced LD could be conducted to carry out LD mapping based on a candidate gene approach, for example, as used to dissect the genetic architecture of plant shape in rice [75]. In addition, characterization of loci on chromosomes with high LD and regions with extensive LD may disclose important loci related to signatures of domestication and artificial selection used in breeding programs. Finally, this kind of approach could provide a more complete picture of the magnitude and structure of LD in the common bean.

Our findings have fundamental implications for the development of association mapping in the common bean. In particular, it is already evident that the careful evaluation of population structure is a key element. Furthermore, our findings suggest that the degree of kinship among individuals in the population under study is also worthy of special attention. In panels substantially consisting of improved lines, such as those used herein, the bias induced by kinship may be stronger than that of population structure itself.

Finally, we would stress the need to take account of one-off LD patterns in genomic regions in which studies have detected significant associations with phenotypic traits. Based on this analysis, it will be possible to outline strategies for exploiting these regions, with the aim of identifying candidate genes involved in trait inheritance.

\section{Conclusions}

This study shows that LD estimates decay dramatically if population structure is taken into account, and especially the degree of kinship among accessions of cultivated common beans on the basis of information on thousands of SNPs. LD measurements vary from one chromosomal region to another and, as expected, are higher in pericentromeric regions. We also found evidence of LD between inter-chromosome loci, suggesting that the breeding process and the species crossing system may have contributed to LD magnitude, since the bias due to population structure and kinship was corrected for. Importantly, the LD estimates herein may influence our ability to localize important genes on the basis of association mapping studies in P. vulgaris.

Supplementary Materials: The following are available online at http:/ / www.mdpi.com/2073-4425/10/1/5/s1. Figure S1: Exploratory analysis of raw data sets of SNPs generated by ApeKI-GBS technology from the IAC panel (82,680 SNPs); Figure S2: Minor allele frequency distribution of SNPs before (pink) and after (blue) imputation, from the IAC panel; Table S1: IAC diversity panel: classification according to institution of origin, type of phaseolin, gene pool, grain size, and commercial group; Table S2: Imputation analysis parameters: window size and accuracy of SNPs generated by ApeKI-GBS technology in the IAC diversity panel; Table S3: Chromosome position, alleles, minor allele frequency (MAF), and genotypes of 10,362 filtered SNPs generated by ApeKI-GBS technology in the IAC diversity panel.

Author Contributions: Conceptualization, A.L.D. and M.LC.V.; Methodology, A.L.D.; Formal Analysis, A.L.D., G.R.A.M., and A.A.F.G.; Investigation, A.L.D.; Resources, J.M.K.C.P., L.L.B.R., A.F.C., and M.L.C.V.; Data Curation, A.L.D. and G.R.A.M.; Writing-Original Draft Preparation, A.L.D.; Writing-Review \& Editing, W.G., Z.P.C., and M.L.C.V.; Supervision, M.L.C.V.; Project Administration, M.L.C.V.; Funding Acquisition, M.L.C.V.

Funding: This research was funded by the following Brazilian Institutions: Fundação de Amparo à Pesquisa do Estado de São Paulo, grant number 2014/06647-9; Conselho Nacional de Desenvolvimento Científico e Tecnológico, grant number 454329/2014-8; and Coordenação de Aperfeiçoamento de Ensino Superior.

Acknowledgments: The authors are grateful to Stéphane Nicolas for providing the optimized version of 'LD.Measures' and Steve Simmons for proofreading the manuscript. 
Conflicts of Interest: The authors declare no conflict of interest.

\section{References}

1. Gepts, P.; Beavis, W.D.; Brummer, E.C.; Shoemaker, R.C.; Stalker, H.T.; Weeden, N.F.; Young, N.D. Legumes as a model plant family. Genomics for food and feed report of the cross-legume advances through genomics conference. Plant Physiol. 2005, 137, 1228-1235. [CrossRef] [PubMed]

2. Debouck, D.G.; Toro, O.; Paredes, O.M.; Johnson, W.C.; Gepts, P. Genetic diversity and ecological distribution of Phaseolus vulgaris (Fabaceae) in northwestern South America. Econ. Bot. 1993, 47, 408-423. [CrossRef]

3. Gepts, P.; Osborn, T.C.; Rashka, K.; Bliss, F.A. Phaseolin-protein variability in wild forms and landraces of the common bean (Phaseolus vulgaris): Evidence for multiple centers of domestication. Econ. Bot. 1986, 40, 451-468. [CrossRef]

4. Kwak, M.; Gepts, P. Structure of genetic diversity in the two major gene pools of common bean (Phaseolus vulgaris L., Fabaceae). Theor. Appl. Genet. 2009, 118, 979-992. [CrossRef] [PubMed]

5. Bitocchi, E.; Nanni, L.; Bellucci, E.; Rossi, M.; Giardini, A.; Zeuli, P.S.; Logozzo, G.; Stougaard, J.; McClean, P.; Attene, G.; et al. Mesoamerican origin of the common bean (Phaseolus vulgaris L.) is revealed by sequence data. Proc. Natl. Acad. Sci. USA 2012. [CrossRef] [PubMed]

6. Mamidi, S.; Rossi, M.; Moghaddam, S.M.; Annam, D.; Lee, R.; Papa, R.; McClean, P.E. Demographic factors shaped diversity in the two gene pools of wild common bean Phaseolus vulgaris L. Heredity 2013, 110, 267-276. [CrossRef] [PubMed]

7. Myers, J.R.; Kmiecik, K. Common bean: Economic importance and relevance to biological science research. In The Common Bean Genome; Pérez de la Vega, M., Santalla, M., Marsolais, F., Eds.; Springer International Publishing: Cham, Switzerland, 2017; pp. 1-20, ISBN 978-3-319-63526-2.

8. Beebe, S. Common bean breeding in the tropics. In Plant Breeding Reviews; Janick, J., Ed.; Wiley Online Books; John Wiley \& Sons, Inc.: New York, NY, USA, 2012; pp. 357-412, ISBN 9781118358566.

9. Jain, S.K.; Allard, R.W. The Effects of linkage, epistasis, and inbreeding on population changes under selection. Genetics 1966, 53, 633-659. [PubMed]

10. Flint-Garcia, S.A.; Thornsberry, J.M.; Buckler IV, E.S. Structure of linkage disequilibrium in plants. Annu. Rev. Plant Biol. 2003, 54, 357-374. [CrossRef] [PubMed]

11. Freyre, R.; Skroch, P.W.; Geffroy, V.; Adam-Blondon, A.-F.; Shirmohamadali, A.; Johnson, W.C.; Llaca, V.; Nodari, R.O.; Pereira, P.A.; Tsai, S.-M.; et al. Towards an integrated linkage map of common bean. 4. Development of a core linkage map and alignment of RFLP maps. Theor. Appl. Genet. 1998, 97, 847-856. [CrossRef]

12. Blair, M.W.; Pedraza, F.; Buendia, H.F.; Gaitan-Solis, E.; Beebe, S.E.; Gepts, P.; Tohme, J. Development of a genome-wide anchored microsatellite map for common bean (Phaseolus vulgaris L.). Theor. Appl. Genet. 2003, 107, 1362-1374. [CrossRef] [PubMed]

13. Miklas, P.N.; Kelly, J.D.; Beebe, S.E.; Blair, M.W. Common bean breeding for resistance against biotic and abiotic stresses: From classical to MAS breeding. Euphytica 2006, 147, 105-131. [CrossRef]

14. Checa, O.; Blair, M. Mapping QTL for climbing ability and component traits in common bean (Phaseolus vulgaris L.). Mol. Breed. 2008, 22, 201-215. [CrossRef]

15. Hanai, L.R.; Santini, L.; Camargo, L.E.A.; Fungaro, M.H.P.; Gepts, P.; Tsai, S.M.; Vieira, M.L.C. Extension of the core map of common bean with EST-SSR, RGA, AFLP, and putative functional markers. Mol. Breed. 2010, 25, 25-45. [CrossRef] [PubMed]

16. Campos, T.; Oblessuc, P.R.; Sforça, D.A.; Cardoso, J.M.K.; Baroni, R.M.; de Sousa, A.C.B.; Carbonell, S.A.M.; Chioratto, A.F.; Garcia, A.A.F.; Rubiano, L.B.; et al. Inheritance of growth habit detected by genetic linkage analysis using microsatellites in the common bean (Phaseolus vulgaris L.). Mol. Breed. 2011, 27, 549-560. [CrossRef]

17. Oblessuc, P.; Baroni, R.; Garcia, A.A.; Chioratto, A.; Carbonell, S.A.; Camargo, L.E.; Benchimol, L. Mapping of angular leaf spot resistance QTL in common bean (Phaseolus vulgaris L.) under different environments. BMC Genet. 2012, 13, 50. [CrossRef] [PubMed]

18. Oblessuc, P.R.; Baroni, R.M.; da Silva Pereira, G.; Chiorato, A.F.; Carbonell, S.A.M.; Briñez, B.; Da Costa, E.; Silva, L.; Garcia, A.A.F.; Camargo, L.E.A.; et al. Quantitative analysis of race-specific resistance to Colletotrichum lindemuthianum in common bean. Mol. Breed. 2014, 34, 1313-1329. [CrossRef] 
19. Keller, B.; Manzanares, C.; Jara, C.; Lobaton, J.D.; Studer, B.; Raatz, B. Fine-mapping of a major QTL controlling angular leaf spot resistance in common bean (Phaseolus vulgaris L.). Theor. Appl. Genet. 2015, 128, 813-826. [CrossRef]

20. Oraguzie, N.C.; Rikkerink, E.H.A.; Gardiner, S.E.; Silva, H.N. Association Mapping in Plants; Springer: New York, NY, USA, 2007.

21. Shi, C.; Navabi, A.; Yu, K. Association mapping of common bacterial blight resistance QTL in Ontario bean breeding populations. BMC Plant Biol. 2011, 11, 52. [CrossRef]

22. Tock, A.J.; Fourie, D.; Walley, P.G.; Holub, E.B.; Soler, A.; Cichy, K.A.; Pastor-Corrales, M.A.; Song, Q.; Porch, T.G.; Hart, J.P.; et al. Genome-Wide linkage and association mapping of Halo Blight resistance in common bean to race 6 of the globally important bacterial pathogen. Front. Plant Sci. 2017, 8. [CrossRef]

23. Perseguini, J.M.K.C.; Oblessuc, P.R.; Rosa, J.R.B.F.; Gomes, K.A.; Chiorato, A.F.; Carbonell, S.A.M.; Garcia, A.A.F.; Vianello, R.P.; Benchimol-Reis, L.L. Genome-wide association studies of anthracnose and angular leaf spot resistance in common bean (Phaseolus vulgaris L.). PLoS ONE 2016, 11, e0150506. [CrossRef]

24. Galeano, C.H.; Cortés, A.J.; Fernández, A.C.; Soler, Á.; Franco-Herrera, N.; Makunde, G.; Vanderleyden, J.; Blair, M.W. Gene-Based Single nucleotide polymorphism markers for genetic and association mapping in common bean. BMC Genet. 2012, 13, 48. [CrossRef] [PubMed]

25. Nemli, S.; Asciogul, T.K.; Kaya, H.B.; Kahraman, A.; Eşiyok, D.; Tanyolac, B. Association mapping for five agronomic traits in the common bean (Phaseolus vulgaris L.). J. Sci. Food Agric. 2014, 94, 3141-3151. [CrossRef] [PubMed]

26. Kamfwa, K.; Cichy, K.A.; Kelly, J.D. Genome-wide association study of agronomic traits in common bean. Plant Genome 2015, 8. [CrossRef]

27. Ates, D.; Asciogul, T.K.; Nemli, S.; Erdogmus, S.; Esiyok, D.; Tanyolac, M.B. Association mapping of days to flowering in common bean (Phaseolus vulgaris L.) revealed by DArT markers. Mol. Breed. 2018, 38. [CrossRef]

28. Nascimento, M.; Nascimento, A.C.C.; e Silva, F.F.; Barili, L.D.; do Vale, N.M.; Carneiro, J.E.; Cruz, C.D.; Carneiro, P.C.S.; Serão, N.V.L. Quantile regression for genome-wide association study of flowering time-related traits in common bean. PLoS ONE 2018, 13, e0190303. [CrossRef] [PubMed]

29. Cichy, K.A.; Wiesinger, J.A.; Mendoza, F.A. Genetic diversity and genome-wide association analysis of cooking time in dry bean (Phaseolus vulgaris L.). Theor. Appl. Genet. 2015, 128, 1555-1567. [CrossRef] [PubMed]

30. Pritchard, J.K.; Przeworski, M. Linkage disequilibrium in humans: Models and data. Am. J. Hum. Genet. 2001, 69, 1-14. [CrossRef] [PubMed]

31. Stram, D.O. Tag SNP selection for association studies. Genet. Epidemiol. 2004, 27, 365-374. [CrossRef]

32. Hedrick, P.W. Gametic disequilibrium measures: Proceed with caution. Genetics 1987, 117, 331-341.

33. Hill, W.G.; Robertson, A. Linkage disequilibrium in finite populations. Theor. Appl. Genet. 1968, 38, $226-231$. [CrossRef]

34. Yu, J.; Pressoir, G.; Briggs, W.H.; Vroh Bi, I.; Yamasaki, M.; Doebley, J.F.; McMullen, M.D.; Gaut, B.S.; Nielsen, D.M.; Holland, J.B.; et al. A unified mixed-model method for association mapping that accounts for multiple levels of relatedness. Nat. Genet. 2006, 38, 203-208. [CrossRef] [PubMed]

35. Mangin, B.; Siberchicot, A.; Nicolas, S.; Doligez, A.; This, P.; Cierco-Ayrolles, C. Novel measures of linkage disequilibrium that correct the bias due to population structure and relatedness. Heredity 2012, 108, 285-291. [CrossRef] [PubMed]

36. Cericola, F.; Portis, E.; Lanteri, S.; Toppino, L.; Barchi, L.; Acciarri, N.; Pulcini, L.; Sala, T.; Rotino, G. Linkage disequilibrium and genome-wide association analysis for anthocyanin pigmentation and fruit color in eggplant. BMC Genom. 2014, 15, 896. [CrossRef] [PubMed]

37. Graebner, R.C.; Wise, M.; Cuesta-Marcos, A.; Geniza, M.; Blake, T.; Blake, V.C.; Butler, J.; Chao, S.; Hole, D.J.; Horsley, R.; et al. Quantitative trait loci associated with the tocochromanol (vitamin E) pathway in barley. PLoS ONE 2015, 10, e0133767. [CrossRef] [PubMed]

38. Mangin, B.; Sandron, F.; Henry, K.; Devaux, B.; Willems, G.; Devaux, P.; Goudemand, E. Breeding patterns and cultivated beets origins by genetic diversity and linkage disequilibrium analyses. Theor. Appl. Genet. 2015, 128, 2255-2271. [CrossRef] [PubMed]

39. Huang, Y.-F.; Poland, J.A.; Wight, C.P.; Jackson, E.W.; Tinker, N.A. Using genotyping-by-sequencing (GBS) for genomic discovery in cultivated oat. PLoS ONE 2014, 9, e102448. [CrossRef] [PubMed] 
40. Kumar, S.; Kirk, C.; Deng, C.; Wiedow, C.; Knaebel, M.; Brewer, L. Genotyping-by-sequencing of pear (Pyrus spp.) accessions unravels novel patterns of genetic diversity and selection footprints. Hortic. Res. 2017, 4, 17015. [CrossRef]

41. Nicolas, S.D.; Péros, J.-P.; Lacombe, T.; Launay, A.; Le Paslier, M.-C.; Bérard, A.; Mangin, B.; Valière, S.; Martins, F.; Le Cunff, L.; et al. Genetic diversity, linkage disequilibrium and power of a large grapevine (Vitis vinifera L) diversity panel newly designed for association studies. BMC Plant Biol. 2016, 16. [CrossRef]

42. Papa, R.; Acosta, J.; Delgado-Salinas, A.; Gepts, P. A genome-wide analysis of differentiation between wild and domesticated Phaseolus vulgaris from Mesoamerica. Theor. Appl. Genet. 2005, 111, 1147-1158. [CrossRef]

43. Papa, R.; Bellucci, E.; Rossi, M.; Leonardi, S.; Rau, D.; Gepts, P.; Nanni, L.; Attene, G. Tagging the signatures of domestication in common bean (Phaseolus vulgaris) by means of pooled DNA samples. Ann. Bot. 2007, 100, 1039-1051. [CrossRef]

44. Blair, M.W.; Cortés, A.J.; Farmer, A.D.; Huang, W.; Ambachew, D.; Penmetsa, R.V.; Carrasquilla-Garcia, N.; Assefa, T.; Cannon, S.B. Uneven recombination rate and linkage disequilibrium across a reference SNP map for common bean (Phaseolus vulgaris L.). PLoS ONE 2018, 13, e0189597. [CrossRef]

45. Campa, A.; Murube, E.; Ferreira, J.J. Genetic diversity, population structure, and linkage disequilibrium in a spanish common bean diversity panel revealed through genotyping-by-sequencing. Genes (Basel) 2018, 9, 518. [CrossRef] [PubMed]

46. Burle, M.L.; Fonseca, J.R.; Kami, J.A.; Gepts, P. Microsatellite diversity and genetic structure among common bean (Phaseolus vulgaris L.) landraces in Brazil, a secondary center of diversity. Theor. Appl. Genet. 2010, 121, 801-813. [CrossRef] [PubMed]

47. Rossi, M.; Bitocchi, E.; Bellucci, E.; Nanni, L.; Rau, D.; Attene, G.; Papa, R. Linkage disequilibrium and population structure in wild and domesticated populations of Phaseolus vulgaris L. Evol. Appl. 2009, 2, 504-522. [CrossRef] [PubMed]

48. Valdisser, P.A.M.R.; Pereira, W.J.; Almeida Filho, J.E.; Müller, B.S.F.; Coelho, G.R.C.; de Menezes, I.P.P.; Vianna, J.P.G.; Zucchi, M.I.; Lanna, A.C.; Coelho, A.S.G.; et al. In-depth genome characterization of a Brazilian common bean core collection using DArTseq high-density SNP genotyping. BMC Genom. 2017, 18. [CrossRef] [PubMed]

49. Resende, R.T.; de Resende, M.D.V.; Azevedo, C.F.; Fonseca e Silva, F.; Melo, L.C.; Pereira, H.S.; Souza, T.L.P.O.; Valdisser, P.A.M.R.; Brondani, C.; Vianello, R.P. Genome-wide association and regional heritability mapping of plant architecture, lodging and productivity in Phaseolus vulgaris. G3 Genes Genomes Genet. 2018, 8, 2841-2854. [CrossRef]

50. Nodari, R.O.; Tsail, S.M.; Gilbertson, R.L.; Gepts, P. Towards an integrated linkage map of common bean 2. Development of an RFLP-based linkage map. Theor. Appl. Genet. 1993, 85. [CrossRef] [PubMed]

51. Ferreira, S.; Gomes, L.A.A.; Maluf, W.R.; Furtini, I.V.; Campos, V.P. Genetic control of resistance to Meloidogyne incognita race 1 in the Brazilian common bean (Phaseolus vulgaris L.) cv. Aporé. Euphytica 2012, 186, 867-873. [CrossRef]

52. Perseguini, J.M.K.C.; Silva, G.M.B.; Rosa, J.R.B.F.; Gazaffi, R.; Marçal, J.F.; Carbonell, S.A.M.; Chiorato, A.F.; Zucchi, M.I.; Garcia, A.A.F.; Benchimol-Reis, L.L. Developing a common bean core collection suitable for association mapping studies. Genet. Mol. Biol. 2015, 38, 67-78. [CrossRef]

53. Kami, J.; Velásquez, V.B.; Debouck, D.G.; Gepts, P. Identification of presumed ancestral DNA sequences of phaseolin in Phaseolus vulgaris. Proc. Natl. Acad. Sci. USA 1995, 92, 1101-1104. [CrossRef]

54. Elshire, R.J.; Glaubitz, J.C.; Sun, Q.; Poland, J.A.; Kawamoto, K.; Buckler, E.S.; Mitchell, S.E. A robust, simple genotyping-by-sequencing (GBS) approach for high diversity species. PLoS ONE 2011, 6, e19379. [CrossRef]

55. Glaubitz, J.C.; Casstevens, T.M.; Lu, F.; Harriman, J.; Elshire, R.J.; Sun, Q.; Buckler, E.S. TASSEL-GBS: A high capacity genotyping by sequencing analysis pipeline. PLoS ONE 2014, 9, e90346. [CrossRef] [PubMed]

56. Schmutz, J.; McClean, P.E.; Mamidi, S.; Wu, G.A.; Cannon, S.B.; Grimwood, J.; Jenkins, J.; Shu, S.; Song, Q.; Chavarro, C.; et al. A reference genome for common bean and genome-wide analysis of dual domestications. Nat. Genet. 2014, 46, 707-713. [CrossRef] [PubMed]

57. Roberts, A.; McMillan, L.; Wang, W.; Parker, J.; Rusyn, I.; Threadgill, D. Inferring missing genotypes in large SNP panels using fast nearest-neighbor searches over sliding windows. Bioinformatics 2007, 23, i401-i407. [CrossRef] [PubMed]

58. R Core Team. R: A Language and Environment for Statistical Computing; R Foundation for Statistical Computing: Vienna, Austria, 2014. 
59. Tracy, C.A.; Widom, H. Level-spacing distributions and the Airy kernel. Commun. Math. Phys. 1994, 159, 151-174. [CrossRef]

60. Patterson, N.; Price, A.L.; Reich, D. Population structure and eigenanalysis. PLoS Genet. 2006, 2, e190. [CrossRef]

61. Nei, M. Molecular Evolutionary Genetics; Columbia University Press: New York, NY, USA, 1987.

62. Tamura, K.; Peterson, D.; Peterson, N.; Stecher, G.; Nei, M.; Kumar, S. MEGA5: Molecular evolutionary genetics analysis using maximum likelihood, evolutionary distance, and maximum parsimony methods. Mol. Biol. Evol. 2011, 28, 2731-2739. [CrossRef] [PubMed]

63. Hayes, B.J.; Goddard, M.E. Technical note: Prediction of breeding values using marker-derived relationship matrices. J. Anim. Sci. 2008, 86, 2089-2092. [CrossRef]

64. Wimmer, V.; Albrecht, T.; Auinger, H.-J.; Schon, C.-C. synbreed: A framework for the analysis of genomic prediction data using R. Bioinformatics 2012, 28, 2086-2087. [CrossRef]

65. Warnes, G.; Leisch, F. Genetics: Population Genetics; Warnes, G., Ed.; R Foundation for Statistical Computing: Vienna, Austria, 2005; pp. 1-36.

66. Benjamini, Y.; Hochberg, Y. Controlling the false discovery rate: A practical and powerful approach to multiple testing. J. R. Stat. Soc. 1995, 57, 289-300. [CrossRef]

67. Marroni, F.; Pinosio, S.; Zaina, G.; Fogolari, F.; Felice, N.; Cattonaro, F.; Morgante, M. Nucleotide diversity and linkage disequilibrium in Populus nigra cinnamyl alcohol dehydrogenase (CAD4) gene. Tree Genet. Genomes 2011, 7, 1011-1023. [CrossRef]

68. Hill, W.G.; Weir, B.S. Variances and covariances of squared linkage disequilibria in finite populations. Theor. Popul. Biol. 1988, 33, 54-78. [CrossRef]

69. Oblessuc, P.R.; Cardoso Perseguini, J.M.K.; Baroni, R.M.; Chiorato, A.F.; Carbonell, S.A.M.; Mondego, J.M.C.; Vidal, R.O.; Camargo, L.E.A.; Benchimol-Reis, L.L. Increasing the density of markers around a major QTL controlling resistance to angular leaf spot in common bean. Theor. Appl. Genet. 2013, 126, 2451-2465. [CrossRef]

70. Bellucci, E.; Bitocchi, E.; Ferrarini, A.; Benazzo, A.; Biagetti, E.; Klie, S.; Minio, A.; Rau, D.; Rodriguez, M.; Panziera, A.; et al. Decreased nucleotide and expression diversity and modified coexpression patterns characterize domestication in the common bean. Plant Cell 2014, 26, 1901-1912. [CrossRef]

71. Zhou, Z.; Jiang, Y.; Wang, Z.; Gou, Z.; Lyu, J.; Li, W.; Yu, Y.; Shu, L.; Zhao, Y.; Ma, Y.; et al. Resequencing 302 wild and cultivated accessions identifies genes related to domestication and improvement in soybean. Nat. Biotechnol. 2015. [CrossRef] [PubMed]

72. Huang, X.; Wei, X.; Sang, T.; Zhao, Q.; Feng, Q.; Zhao, Y.; Li, C.; Zhu, C.; Lu, T.; Zhang, Z.; et al. Genome-wide asociation studies of 14 agronomic traits in rice landraces. Nat. Genet. 2010, 42,961-967. [CrossRef] [PubMed]

73. Bhakta, M.S.; Jones, V.A.; Vallejos, C.E. Punctuated distribution of recombination hotspots and demarcation of pericentromeric regions in Phaseolus vulgaris L. PLoS ONE 2015, 10, e0116822. [CrossRef] [PubMed]

74. Johnson, W.C.; Gepts, P. The role of epistasis in controlling seed yield and other agronomic traits in an Andean $\times$ Mesoamerican cross of common bean (Phaseolus vulgaris L.). Euphytica 2002, 125, 69-79. [CrossRef]

75. Lim, J.-H.; Yang, H.-J.; Jung, K.-H.; Yoo, S.-C.; Paek, N.-C. Quantitative trait locus mapping and candidate gene analysis for plant architecture traits using whole genome re-sequencing in rice. Mol. Cells 2014, 37, 149-160. [CrossRef]

(c) 2018 by the authors. Licensee MDPI, Basel, Switzerland. This article is an open access article distributed under the terms and conditions of the Creative Commons Attribution (CC BY) license (http://creativecommons.org/licenses/by/4.0/). 